\title{
Effect of Sports Activities on Behavioral-Emotional Problems of Students with Intellectual Disability
}

\author{
Fatemeh Farhangi ${ }^{1}$, Ghorban Hemati Alamdarloo ${ }^{1^{*}}$
}

1. Department of Special Education, School of Education \& Psychology, Shiraz University, Shiraz, Iran.

crtation: Farhangi F, Hemati Alamdarloo Gh. Effect of Sports Activities on Behavioral-Emotional Problems of Students with Intellectual Disability. Physical Treatments. 2015; 5(3):145-152.

Article info:

Received: 01 May 2015

Accepted: 02 Sep. 2015

\section{Keywords:}

Students, Sports activities, Behavioral-emotional problems, Mental retardation

\begin{abstract}
A B S T R A C T
Purpose: This study aimed to investigate the effect of sports activities on behavioral-emotional problems of students with intellectual disability.

Methods: Research method was quasi-experimental with pretest-posttest design and the control group. The study population consisted of all students with intellectual disability in Farashband City, Iran who were studying in 2013. The sample comprised 30 students with intellectual disability of Shoorideh School in Farashband City who were selected with convenience sampling method. They were randomly divided into 2 groups of 15 students as experimental and control groups. We used developmental behavior checklist as the instrument for measuring behavioralemotional problems. Before performing sports activities, teachers in both groups administered developmental behavior checklist as the pretest. Then experimental group was provided with the interventional program of sports activities for 24 sessions, 3 sessions per week, and each session lasted 60 minutes. The control group did not receive these sports activities. After performing the interventional program, teachers in both groups again filled developmental behavior checklist, this time as a posttest. Collected data were analyzed using analysis of covariance. Data analysis was done by SPSS version 19 .
\end{abstract}

Results: The mean total score of behavioral-emotional problems and their subscales in the experimental group significantly reduced $(\mathrm{P}<0.01)$.

Conclusion: Sports activities are effective in improving behavioral-emotional problems of students with intellectual disability. Performing sports activities is recommended for the prevention, reduction, and elimination of behavioral-emotonal problems.

\section{Introduction}

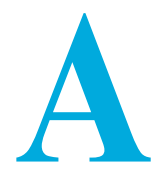

ccording to training instructions for people with disabilities, behavioral-emotional problems are due to a condition which has one or more of the following features; emerging in long-term and with intensity and affecting academic performance of the child. These problems include learning disabilities resulted from the intellectual, sensory, or physical factors; inability to build or maintain satisfactory relationships with teachers and peers; existence of all kinds of inappropriate behaviors and emotions under ordinary circumstances of life; persisting sadness and depression; and showing symptoms such as fear or physical symptoms in

\section{* Corresponding Author:}

Ghorban Hemati Alamdarloo, PhD

Address: Department of Special Education, School of Education \& Psychology, Shiraz University, Shiraz, Iran.

Phone: +98 (912) 6234096

E-mail: ghemati@shirazu.ac.ir 
facing with personal and academic issues [1]. People with intellectual disability are more likely to have emotional behavioral problems [2]. In comparison with ordinary people, emotional disturbances and behavioral-emotional problems are more common in children with intellectual disability [3]. Likewise, Crnic, Hoffman, Gaze, and Edelbrock [4] stated that people with intellectual disability had more behavioral-emotional problems and showed a wide range of oppositional problems, anxiety, hyperactivity, attention deficit, and communication.

Attacking people or other's belongings and physical abuse such as punching, slapping, kicking, screaming, and selfharm are some problematic behaviors expressed by people with intellectual disability [5]. Having behavioral-emotional problems, these people are sometimes abusive, destructive, unpredictable, irresponsible, quarrelsome, irritable, jealous, and defiant [6]. Also, we can mention that these people are forced to live in slums. Because of behavioralemotional problems, they are usually rejected to participate in parties and other social gatherings, and therefore, are deviated from the normal course of life.

Their seclusion leads to their limitation of using public facilities [7]. In this regard, Henley, Ramsey, and Ozzine [8] suggested that behavioral-emotional problems in children would lead to communication problems. Low levels of self-esteem and lack of self-control are results of behavioral-emotional problems. These people often face difficulties in school adaptation. Also, because teachers do not have necessary knowledge about these children, they show negative reactions towards them, which causes autism in children. To support this, Paterson and Sanson [9] reported that these people did usually fail in reaching their goals and these failures would lead to the emergence of various mental disorders. Matson, Terlonge, Gonzalez, and Rivet [10] believed that children with intellectual disability had behavioral-emotional problems in addition to damaging behavior, which can be in the form of harming their own body (suicide, self-injury) and others such as parents, siblings, or even their caregivers. Generally, most children with intellectual disability and behavioral-emotional problems, have fundamental problems in making close and satisfactory relationships with others. As a result, they lose interest of others and are rejected by people and peers around them [11].

Sports activities are among the various techniques that reduce and eliminate the behavioral-emotional problems in these children. Performing physical and sports activities, in addition to improve and overcome behavioral-emotional problems, teaches children with intellectual disability how to interact with others in a friendly manner and improves their quality of lives. In other words, the correct and appropriate use of sports programs according to the structural and psychological characteristics of the participants, while guaranteeing the physical and mental health, prepares the individual for social life, too [12]. Some of the mentally retarded children do not have healthy shape, fitness, and balance which are essential to maintain their health and safety. Therefore, sport and physical activities activate their lifestyle, improve their mental body image with proper diet, and eventually alleviate their behavioral-emotional problems $[13,14]$.

In other words, sports activities make more acceptable mentally retarded people among their friends and society, activate their cognitive development, give them good physical condition, and bring peace, joy, and stability to their behavior [15]. Doing sports activities, if purposeful and appropriate, while creating physical health, helps develop behaviors that are the prerequisite for social and environmental compatibility [16]. About the privilege of sports activities, Mazhork, Tachelman, and Houser [17] studied the effects of exercise and music on 5 hyperactive children. Their results showed that sports and music improved problems related to their social behavior, the speed of their work, and reduced their hyperactivity disorder.

Fedak [18] also in a study entitled "The effect of exercise on stereotypes of children with autism spectrum disorder" concluded that physical activity reduces the stereotyped behaviors. In addition, Ghanbari, Hashemabadi, and Saadat [19] investigated the effect of rhythmic movements of yoga on social interactions of mentally retarded children and concluded that rhythmic movements of yoga would improve the children's social interactions. In line with these findings, Cureton [20] in a study concluded that sports activities improved the social adaptation of children with intellectual disability. Various studies also have shown that sports activities reduce aggression in children with intellectual disability [2123].

As we have seen, students with intellectual disability and behavioral-emotional problems always make trouble for themselves, their parents, and school. In other words, behavioral-emotional problems of children with intellectual disability impose various physical and psychological problems on their parents and teachers. Therefore, lack of sufficient attention to the behavioral problems of children can lead to higher incidence of chronic problems. On the other hand, according to the literature, no research has examined the impact of sports activities on the behavioral-emotional problems of students with intellectual disability. Because of the poor economic and cultural condition of most families of students with intellectual disability and their inability to use costly treatments (such as medical, paramedical, and psychological treatments), these kinds of studies can be of 
great help to this group. Furthermore, sport classes are easily applicable for those involved in education in all schools without huge costs. Sport (physical activities) can be used as simple treatment without any side effects for behavioralemotional problems of these children.

In this regard, this research aimed to investigate the effect of sports activities on behavioral-emotional problems of students with intellectual disability. This research while filling the previous research niches, took a step towards improving mental health of students with intellectual disability with a simple method without any side effects and prevent the negative consequences of behavioral-emotional problems of these students. The findings of this study will be useful for specialists, planners, teachers, and parents.

\section{Materials and Methods}

This study is quasi-experimental, with pretest-posttest design and the control group in which the effects of the independent variable i.e. sports activities were examined on the dependent variable i.e. behavioral-emotional problems of students with intellectual disability.

\section{The study sample}

The study population consisted of all students with intellectual disability in Farashband City, Iran who were studying in academic year, 2013-2014. The sample comprised 30 students with intellectual disability studying at Shoorideh School in Farashband. They who were selected by convenience sampling method and then randomly divided into two groups: experimental and control.

\section{Instruments}

List of emotional behavioral problems was the study instrument, which was developed by Infeld and Tung [24] in 2002. This list has been prepared for people with intellectual disability aged 4 to 18 years. It contains a form for teachers and one for parents and includes 92 items and checks 5 dimensions of antisocial behavior, autism, communication disorder, anxiety, and social communication. The list is scored based on 5-point Likert-type in the order of 1 to 5 .

Validity and reliability of the questionnaire have been confirmed by Infeld and Tung [24]. In Iran, reliability and validity of the questionnaire have been checked and confirmed by Weisi [25]. The validity of the list in this study has been measured through correlation of score of each dimension with the total score and the correlation results for antisocial behavior, autism, communication disorder, anxiety, and social communication, which were $0.96,0.94$,
$0.81,0.77$, and 0.66 , respectively. Reliability of the list in this study using Cronbach $\alpha$ coefficient was 0.96 . The Cronbach $\alpha$ coefficients for each dimensions of anti-social behavior, autism, communication disorder, anxiety and social communication were $0.93,0.90,0.81,0.79$, and 0.78 , respectively.

\section{Intervention program}

The experimental group performed sports activities for 8 weeks, 3 times a week, and each session was 60 minutes. Each session consists of 3 parts as follows:

- Warm up exercise and walk with 15 minutes of stretching and movement,

- The main part of exercise, which lasted 40 minutes. Exercises of this part included pushing feet paw to the wall, backward walking ( $2 \mathrm{~m})$, jump into the air, rotating 180 degrees and landing on the feet (at least with 3 seconds pause), squatting (3 times), jumping rope and hopping and crossing the distances of ladder placed horizontally, 5 penalty kicks, dribbling the soccer ball between obstacles, running downhill, running uphill, running with back and knees high movements on downhill, running with scissors movements and wide feet walk in uphill, walking backward and jump 180 degrees and the angel movement and sprints of $15 \mathrm{~m}$ with starting in sitting position, static balance exercises two-by-two, put the ball in the air, dodge, sitting on the chair when hearing the sound of the whistle, zigzag running between obstacles, running by side, running a continuous rotation, and performing sport games,

- Five minutes cool-down and stretching.

\section{Procedure}

After obtaining permission from the Department of Education in Farashband City and coordination with the principal of special school for students with intellectual disability, the subjects were selected and were randomly divided into experimental and control groups. Then, both groups took pretest of behavioral-emotional problems. Experimental group performed aerobic and resistance activities in 24 sessions of 60 minutes during 8 weeks. After ending intervention program, both control and experimental groups took posttest by developmental behavior checklist.

\section{Statistical analysis}

For descriptive analyses, statistical indexes such as frequency, frequency percentage, mean and standard deviation were 
calculated and for inferential statistics, analysis of covariance was used. All data were analyzed using SPSS version 19.

\section{Results}

Of 30 study subjects, 15 ( 8 girls and 7 boys) belonged to the experimental group. Their age range was 8 to 13 with the mean of 9.53 and the standard deviation of 2.29 years. Also, 15 ( 8 girls and 7 boys) belonged to the control group and their age range was 8 to 13 with the mean of 9.42 and standard deviation of 2.29 years. It is worth noting that independent t-test results showed no significant difference between 2 groups with regard to age.

Table 1 presents the mean and standard deviation of pretest and posttest results of subjects in both control and experimental groups. According to Table 1, the mean total score of behavioral-emotional problems as well as subscales of social communication, anxiety, communication disorder, autism, and antisocial behavior in the pretest are almost similar in experimental and control groups. But after intervention, the mean total score and subscales of behavioralemotional problems dropped in the experimental group. To see if this decline is statistically significant, analysis of covariance was used. However, prior to the analysis of co- variance, its main assumptions were investigated. For this purpose, the Kolmogorov-Smirnov test was used to check the assumption of the normal distribution, the Levene's test was used to check the assumption of homogeneity of variances, and an interaction of pretest and the independent variable was used for the assumption of the same slope of the regression line. The test results confirmed the assumptions of analysis of covariance.

The first hypothesis of the research states that sports activities have a significant effect on the behavioral-emotional problems of students with intellectual disability. To test this hypothesis, analysis of covariance was used. Its results are presented in Table 2. According to Table 2, pretest as an auxiliary variable had a significant effect on the obtained results. Considering pretest scores as an auxiliary variable for performing sports activities on the entire behavioralemotional problems, lead to significant differences between control and experimental groups $(\mathrm{P}<0.01)$. As a result, 69\% of the variance in posttest was explained by the effect of sports activities on behavioral-emotional problems.

The second research hypothesis states that sports activities have significant effect on the subscales of behavioralemotional problems in students with intellectual disability.

Table 1. The mean and standard deviation of the pretest and posttest results of experimental and control groups.

\begin{tabular}{|c|c|c|c|c|c|c|c|c|}
\hline \multirow{3}{*}{ Variable } & \multicolumn{4}{|c|}{ Experimental } & \multicolumn{4}{|c|}{ Control } \\
\hline & \multicolumn{2}{|c|}{ Pretest } & \multicolumn{2}{|c|}{ Posttest } & \multicolumn{2}{|c|}{ Pretest } & \multicolumn{2}{|c|}{ Posttest } \\
\hline & Mean & SD & Mean & SD & Mean & SD & Mean & SD \\
\hline Social communication & 8.66 & 4.70 & 6.33 & 3.53 & 9.13 & 3.48 & 9.20 & 3.46 \\
\hline Anxiety & 9.53 & 4.32 & 7.20 & 3.18 & 9.26 & 4.36 & 8.20 & 4.36 \\
\hline Communication disorder & 9.93 & 3.49 & 7.27 & 3.57 & 8.93 & 3.45 & 10.33 & 3.88 \\
\hline Autism & 31.46 & 14.88 & 28.93 & 14.10 & 31.60 & 13.99 & 31.00 & 13.35 \\
\hline Antisocial behavior & 32.73 & 12.84 & 29.35 & 13.11 & 33.14 & 14.08 & 33.33 & 12.98 \\
\hline Behavioral-emotional problems & 92.30 & 10.08 & 79.06 & 12.13 & 92.06 & 10.30 & 92.28 & 11.06 \\
\hline
\end{tabular}

Table 2. Results of analysis of covariance for the control and experimental groups with regard to the total score of behavioralemotional problems.

\begin{tabular}{ccccccc}
\hline Source of change & Sum of squares & df & Mean of sum of squares & F & Sig. & ETA separation factor \\
\hline Pretest & 4208.85 & 1 & 4208.85 & 230.47 & 0.01 & 0.88 \\
Group & 1189.07 & 1 & 1198.07 & 68.45 & 0.01 & -1 \\
Error & 530.38 & 27 & 19.98 & -- & -- & -- \\
Total & -- & 30 & -- & -- \\
\hline
\end{tabular}


Table 3. The results of analysis of covariance for the control and experimental groups with regard to subscales of behavioralemotional problems.

\begin{tabular}{|c|c|c|c|c|c|c|c|}
\hline $\begin{array}{l}\text { Source of } \\
\text { change }\end{array}$ & $\begin{array}{l}\text { Dependent } \\
\text { variable }\end{array}$ & Sum of squares & df & $\begin{array}{l}\text { Mean of sum } \\
\text { of squares }\end{array}$ & $\mathbf{F}$ & Sig. & ETA separation factor \\
\hline \multirow{5}{*}{$\begin{array}{l}\text { Groups (ex- } \\
\text { perimental and } \\
\text { control) }\end{array}$} & $\begin{array}{l}\text { Social communi- } \\
\text { cation }\end{array}$ & 104.92 & 1 & 104.92 & 17.38 & 0.01 & 0.39 \\
\hline & Anxiety & 43.65 & 1 & 43.65 & 6.63 & 0.01 & 0.19 \\
\hline & $\begin{array}{c}\text { Communication } \\
\text { disorder }\end{array}$ & 121.115 & 1 & 121.115 & 59.53 & 0.01 & 0.68 \\
\hline & Autism & 1114.13 & 1 & 1114.13 & 29.97 & 0.01 & 0.52 \\
\hline & $\begin{array}{l}\text { Antisocial } \\
\text { behavior }\end{array}$ & 1461.81 & 1 & 1461.81 & 57.61 & 0.01 & 0.68 \\
\hline
\end{tabular}

To test this hypothesis, analysis of covariance was used, the results of which are presented in Table 3.

\section{Discussion}

This study aimed to investigate the effect of sports activities on the behavioral-emotional problems of students with intellectual disability. Research results indicate that sports activities have significant effect on the posttest score of behavioral-emotional problems and its subscales and has decreased behavioral-emotional problems of students with intellectual disability. These findings are consistent with the findings of Tello [18], Ghobari Bonab [21], Shojaei and Hemmati Alamdarloo [23], Chan et al. [26], Keshavarz et al. [27], Ray Bratton et al. [28], Lyman [29], Ryan [30], Salehpour et al. [31], and Karami et al. [32].

To explain these beneficial results, we can refer to general behavior of mentally retarded students. Successive failures in mentally retarded children lead to their low self-confidence, disappointment, autism, anxiety, aggression, and expanded negative feelings which need to be discharged. Different types of sports and physical activities help them to release these feelings and negative emotions in controlled situations and accordingly their behavioral-emotional problems decrease [34].

Also people in sports groups acquire social, behavioral, psychological, and communication skills necessary for their personal or social relationships which lead to their appropriate response to other people's behavior and also reduce their behavioral-emotional problems [21]. In addition, by sports activities, body glands begin to secrete relaxing chemicals which reduce hyperactivity, aggression, and depression [26].

To explain the effect of physical exercise on the social interaction of students with intellectual disability, it can be argued that sports activities and games affect all social activities and personality development of children with intellectual disability. Sport as a cultural item affects the socialization process. Participation in sports activities contribute to positive changes and growth in social behavior of students [34]. Because of creating the appropriate environment to make extensive interactions, sports activities are effective in improving interpersonal communication. In other words, sports push curtain of embarrassment aside and prepares the person to enter the community $[35,36]$.

To account for the effect of physical exercise on the anxiety of students with intellectual disability it can be said that due to successive failures, self-denial, low self-esteem and being ridiculed by others, mentally retarded children are constantly exposed to stress and worried about negative feedback of their behavior. Furthermore, due to their mistakes, they were ridiculed in the community and even in their families. They are sometimes labelled as crazy, retarded, and clumsy. Finally, they believe that they are unable to do anything. They have continuous anxiety of being scorned and experience anger of people around them [36]. In other words, such a situation makes sympathetic responses stronger, adrenaline gland activity increases and the person becomes anxious. In this situation, exercise and sports activities result in decreasing sympathetic arousal and thus suppress anxiety [37].

Also, in explaining the effect of physical exercise on communication disorder of students with intellectual disability, we can say that sports activities, in addition to induce relaxation, are effective on strengthening the muscles of the tongue, mouth, and face [28]. These effects directly improve talking and communication disorders. Moreover, sports activities increase level of self-confidence and social communication and reduce people's fear and anxiety [38] and thereby improve communication disorders.

To make clear the effect of physical exercise on the autism in children with intellectual disability, we have to describe this disorder first. Autism is a developmental disorder with 
deficits in social interaction, verbal and non-verbal communication, interests and stereotyped behavior and activities. Sport has a certain programed features and principles that impacts positively on some parts of autistic children. For example, it helps them initiate the communication, how to interact in different social situations, motivate them, and also rises the confidence in these children to maintain interaction with others. It helps them have more eye contact with friends and others and show more favorable behaviors. Therefore, sport helps these children to stay away from their cold world and start social relationships [39].

To explain the effect of sports activities on antisocial behavior of children with intellectual disability, it can be mentioned that social experience gained from the activities of physical education is very influential in solving social problems. Their rational decisions, moral judgments, and experience in sports fields can be transferred to real life. Imitating the leaders and coaches in word and deed which is important for participants in sports activities create desirable and outstanding traits in students. Controlling emotions, compliance with laws, and respect for social orders are among the habits that are likely to be learned during sports. Moreover, because performing sports activities is done according to certain rules and regulations, compliance is mandatory for all participants. As a result, the game is an opportunity to teach observing the rules, respecting others, and increasing self-confidence [40]. All the aforementioned factors combined may decrease antisocial behavior of children with intellectual disability.

Regarding the limitations of this study, we can refer to impossibility of controlling physical activities of students outside the set of exercises determined. It is suggested that future researchers study the effects of sports activities on the behavioral-emotional problems of other groups with special needs. Finally, we suggest that special education officials and school principals of students with intellectual disability pay special attention to sports class of students. Holding training workshops for parents and teachers of students with intellectual disability about the impact of physical activity on the behavioral-emotional problems will be very useful.

\section{Acknowledgments}

This paper was extracted from the second author' MSc. thesis. We are sincerely grateful to all teachers of mentally retarded students working with Education Department of Farashband City who helped us in conducting this study.

\section{Conflict of Interests}

The author(s) declared no potential conflicts of interest with respect to the research, authorship, and/or publication of this article.

\section{References}

[1] Werts MG, Culatta R, Tompkins JR. Fundamentals of special education: what every teacher needs to know. New Jersey: Prentice Hall; 2007.

[2] Floyd FJ, Gallagher EM. Parental stress, care demands, and use of support services for school-age children with disabilities and behavior problems. Family Relations. 1997; 46:359-71.

[3] Minshawi NF. Relationship between problem behaviors, function, and adaptive skills in individuals with intellectual disabilities [PhD thesis]. Louisiana: Louisiana State University; 2007.

[4] Crnic K, Hoffman C, Gaze C, Edelbrock C. Understanding the emergence of behavior problems in young children with developmental delays. Infants \& Young Children. 2004; 17(3):223-35.

[5] Allen D. Recent research on physical aggression in persons with intellectual disability: an overview. Journal of Intellectual and Developmental Disability. 2000; 25(1):41-57.

[6] Sukoco P. Social behaviors of mentally-retarded students in physical education learning. Journal of Education. 2010; 1(2):85-90.

[7] Buelow JM, Austin JK, Perkins SM, Shen J, Dunn DW, Fastenau PS. Behavior and mental health problems in children with epilepsy and low IQ. Developmental Medicine \& Child Neurology. 2003; 45(10):683-92

[8] Henley M. Characteristics of and strategies for teaching students with mild disabilities. 6 ed. London: Pearson; 2002

[9] Paterson G, Sanson A. The association of behavioural adjustment to temperament, parenting and family characteristics among 5-year-old children. Social Development. 1999; 8(3):293-309.

[10] Matson JL, Terlonge C, González ML, Rivet T. An evaluation of social and adaptive skills in adults with bipolar disorder and severe/profound intellectual disability. Research in developmental disabilities. 2006; 27(6):681-87.

[11] Shokoohi-Yekta M, Parand A. [Behavioral disorders of children and adolesents (Persian)]. Tehran: Tabib Press; 2006.

[12] Baloochi A. [Relashenship between motor performance, IQ and adaptive behavior (Persian)] [MA thesis]. Tehran: Tarbiyat Modares University; 2001.

[13] Votruba SB, Horvitz MA, Schoeller DA. The role of exercise in the treatment of obesity. Nutrition. 2000;16(3):179-88

[14] Wind WM, Schwend RM, Larson J. Sports for the physically challenged child. Journal of the American Academy of Orthopaedic Surgeons. 2004; 12(2):126-37.

[15] Afrooz GA. [Mentally retarded child (Persian)]. Tehran: University of Tehran; 2006 
[16] Aslankhani MA. [Effect of sport in development of social skills of students (Persian)]. Zivar-e Varzesh. 2001; 2(8):63-65.

[17] Majorek M, Tüchelmann T, Heusser P. Therapeutic Eurythmymovement therapy for children with attention deficit hyperactivity disorder (ADHD): a pilot study. Complementary therapies in Nursing and Midwifery. 2004; 10(1):46-53.

[18] Fedak AT. The effects of physical activity on the stereotypic behaviors of children with autism spectrum disorder $[\mathrm{PhD}$ thesis]. Texas: Texas State University; 2012.

[19] Ghanbari B, Saadat M. [Effect of rhythmic movements of yoga on social interactions mentally retarded children (boys) elementary schools in Sangan (Persian)]. Studies of Education and Psychology. 2011; 11(1):171-88.

[20] Cureton TK. Improvement of psychological states by means of exercise-fitness programs. Journal of the Association for physical and Mental Rehabilitation. 1963; 17(2):14-25.

[21] Ghobari Bonab B, Nabavi M. [Effect of exercise in the morning to reduce aggression in educable mentally retarded children (Persian)]. Journal of Psychology \& Education. 2003; 33(1):13954.

[22] Aghayousefi AR, Alipour A. [The effectiveness of music-harmonic movement therapy on aggressive behaviors in children with moderate to severe intellectual disability (Persian)]. Research on Exceptional Children. 2010; 10(4):343-50.

[23] Shojaee S, Hemati Alamdarloo Gh. [Effect of exercise in the morning to reduce aggression in educable mentally retarded children (Persian)]. Research on Exceptional Children. 2006; 22(4): 855-70.

[24] Einfeld SL, Tonge BJ. Manual for the developmental behaviour checklist: primary carer version (DBC-P) \& teacher version (DBC-T). Sydney: University of New South Wales; 2002.

[25] Veysi E, Hemati Alamdarloo Gh. [A developmental comparison of emotional/behavioral problems in students with intellectual disability (Persian)]. Middle Eastern Journal of Disability Studies. 2015; 4(4):1-12.

[26] Chan AS, Cheung MC, Sze SL, DeLuca BN. Effect of mind/ body training on children with behavioral and learning problems: a randomized controlled study. New York: Nova Science Publisher Inc.; 2008

[27] Sarli A, Shahbazi M, Bagherzadeh F. Investigating the effectiveness of perceptual-motor tasks on visual and auditory attention of children with attention deficit hyperactivity disorder. Motor Behavior. 2014; 6(15):59-72.

[28] Ray D, Bratton S, Rhine T, Jones L. The effectiveness of play therapy: responding to the critics. International Journal of Play Therapy. 2001; 10(1):85-108.

[29] Layman EM. The contribution of play and sports to emotional health; Psychological aspects of physical education and sport. London: Routledge \& Kegan Paul; 1972.

[30] Ryan N, Marr CM, McGladdery AJ. Survey of cardiac arrhythmias during submaximal and maximal exercise in Thoroughbred racehorses. Equine Veterinary Journal. 2005; 37(3):265-68.

[31] Salehpoor M, Salesi M, Hemati Alamdarloo G. [The effect of exercise on anxiety of adolescents with intellectual disability (Persian)]. Physical Treatments. 2015; 5(1):33-39.
[32] Karami L, Salesi M, Hemati Alamdarloo Gh. [The effect of exercise on aggression in students with intellectual disability (Persian)]. Middle Eastern Journal of Disability Studies. 2014; 4(2):12-19.

[33] Rutter M. Resilience: some conceptual considerations. Journal of Adolescent Health. 1993; 14(8):626-31.

[34] Bakhshayesh Z. [The role of physical education in the development of students (Persian)]. Training \& Physical Education. 2010; 32(3):48-51.

[35] Campbell MA. Value of sandplay as a therapeutic tool for school guidance counsellors. Australian Journal of Guidance and Counselling. 2004; 14(2):211-32.

[36] Greist JH, Klein MH, Eischens RR, Faris J, Gurman AS, Morgan WP. Running as treatment for depression. Comprehensive Psychiatry. 1979; 20(1):41-54.

[37] Mahmoodi Aghdam S, Khademi Kalantari KH, Akbarzadeh Baghban AR, Rezayi M, Rahimi A, Naimee S. [Effect of sustained traction on physical improvements of patients with severe knee osteoarthritis (Persian)]. Journal of Modern Rehabilitation. 2013; 7(3):24-32

[38] Salehpoor M, Salesi M, Hemati Alamdarloo Gh. The effect of exercise on anxiety of adolescents with intellectual disability. Physical Therapy Journal. 2015; 5(1):25-32.

[39] Naghshiniyan S. [Recreational therapy for autistic children (Persian)]. Journal of Exceptional Education. 2004; 27(2):24-27.

[40] Azizabadi Farahani A. [General physical education (Persian)]. Tehran: Peyam-e Noor University Publication; 2005. 
